\title{
SKS splitting beneath Capital area of China*
}

\author{
CHANG Li-jun ${ }^{\star}$ (常利军) WANG Chun-yong (王椿镛) DING Zhi-feng (丁志峰) \\ Institute of Geophysics, China Earthquake Administration, Beijing 100081, China
}

\begin{abstract}
Based on the polarization analysis of teleseismic SKS waveform data recorded at 49 seismic stations in Capital Area Seismograph Network, the SKS fast-wave direction and the delay time between the fast and slow shear waves at each station were determined by using the grid searching method of minimum transverse energy and the stacking analysis method, and then we acquired the image of upper mantle anisotropy in Capital area. In the study area, the fast-wave polarization direction is basically WNW-ESE, and the delay time falls into the interval from $0.56 \mathrm{~s}$ to $1.56 \mathrm{~s}$. The results imply that the upper mantle anisotropy in Capital area is mainly caused by the subduction of the Pacific plate to Eurasian plate. The subduction has resulted in the asthenospheric material deformation in Capital area, and made the alignment of upper mantle peridotite lattice parallel to the deformation direction. And the collision between the Indian and Eurasian plates made the crust of western China thickening and uplifting and material eastwards extruding, and then caused the upper mantle flow eastwards, and made the upper mantle deformation direction parallel to the fast-wave direction. The deformation model of the crust and upper mantle is possibly vertically coherent deformation by comparing the fast-wave polarization direction with the direction of lithospheric extension and the GPS velocity direction.
\end{abstract}

Key words: Capital area; SKS wave; anisotropy; fast-wave direction; deformation CLC number: $\mathrm{P} 315.3^{+} 1 \quad$ Document code: A

\section{Introduction}

Capital area is located in the northern North China where tectonic activity is very intensive and fault distribution is complex. There have occurred numerous strong earthquakes. For example, the 1679 Sanhe-Pinggu earthquake (M8) is the largest event among the recorded historically earthquakes in this area. The 1976 Tangshan earthquake (M7.8) killed totally about 240000 people. The EW-trending Yanshan uplift is in the north of Capital area, the NE-trending Taihang uplift is in the west, the North China Basin is in the south, and Bohai Sea is on the east. The ENE-striking faults are predominate active faults in the study area, where the tectonic movement has been frequent in history. Several major tectonic movements formed a complex geological structure pattern.

Many scholars focus on Capital area due to its special tectonic setting. It has important significance to study the deep structure and dynamics in this region. Seismic anisotropy is an effective method for understanding the crust and upper mantle deformation. The researches on anisotropy can be used not only to understand the intraplate deformation features but also to in-

\footnotetext{
* Received 2008-05-06; accepted in revised form 2008-07-03.

Foundation item: The Special Project for the Fundamental Research and Development of Institute of Geophysics, China Earthquake Administration (DQJB06B06), the National Natural Science Foundation of China (40334041) and the Special Program of the Ministry of Science and Technology of China (2006FY110100).

Contribution No.08FE3011, Institute of Geophysics, China Earthquake Administration.

^ Author for correspondence: ljchang@cea-igp.ac.cn
} 
sight the lithospheric mantle deformation status related to the plate tectonic movements. The fast-wave directions of the crustal anisotropy are mainly NE in Capital area (GAO et al, 1999; LAI et al, 2006; WU et al, 2007), which can indicate the regional maximum horizontal principal compressive stress. The fast-wave directions are partly WNW, which are possibly caused by the Zhangjiakou-Penglai fault belt. In Tangshan area, the near E-W fast-wave direction is consistent with the regional maximum horizontal principal compressive stress and the strike of faults. In western China, some scholars had conducted a series of researches on upper mantle anisotropy (LÜ et al, 1996; DING and ZENG, 1996; JIANG et al, 2001; WANG et al, 2007a; CHANG et al, 2006, 2008). However, because of the insufficient data, the previous study of the upper mantle anisotropy in Capital area is preliminary (Zhao and Zheng, 2005; Liu et al, 2008; ZHENG and GAO, 1994; LUO et al, 2004). Since 2001, Capital Area Seismograph Network has accumulated a lot of broadband digital seismic data, which is greatly helpful to the seismological study on the upper mantle anisotropy and the related geodynamics in the study area.

\section{Seismic data}

We collected teleseismic data from 2002 to 2005 recorded at 49 broadband seismic stations in Capital Area Seismograph Network. The teleseismic events were collected at distance between $85^{\circ}$ and $110^{\circ}$ and with magnitude $M_{\mathrm{S}}>6.0$ for shallow earthquake (focal depth $<150 \mathrm{~km}$ ) or $M_{\mathrm{S}}>5.5$ for deep earthquake (focal depth $>150 \mathrm{~km}$ ). A total of 52 teleseismic events were collected in this study (Figure 1). Most events come from the Fiji-Tonga area in South Pacific Ocean. As a whole, the azimuthal distribution of events meets the requirements of this study.

\section{Analysis method}

The SKS splitting analysis method includes two steps. At first, we use the method of Silver and Chan (1991), i.e., the grid searching method of the minimum transverse energy, to make measurement of the anisotropic parameters and their errors determined by individual event with different azimuth, where $95 \%$ confidence is used to the errors estimation. Then, a group of anisotropic parameters from individual event at a station are stacked by the splitting parameters method similar to that presented by Vinnik et al (1989) (Wolfe and Silver, 1998). For SKS waves with

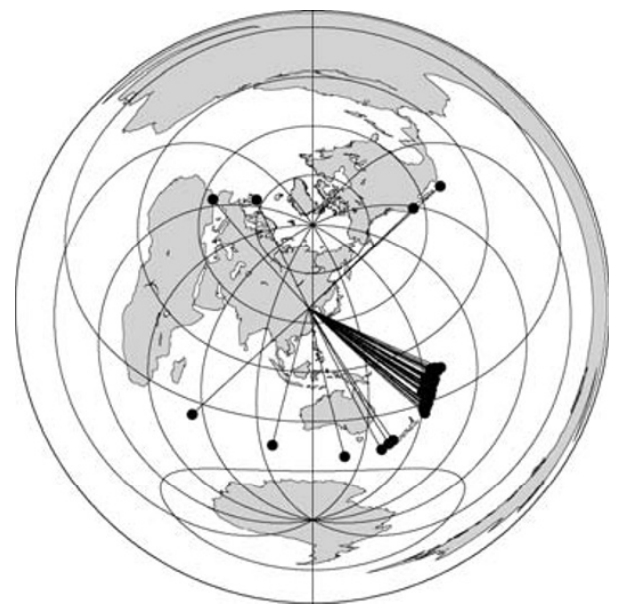

Figure 1 Epicenters of events (black dots) used in the study different azimuths and different signal-to-noise ratios, this method improves the reliability of the splitting result, especially for the stations with larger background noise. The stacking analysis is an effective method to raise the accuracy of SKS splitting measurement at a station (WANG et al, 2007a; CHANG et al, 2008).

When the epicentral distances at $85^{\circ} \sim 110^{\circ}$, SKS wave travels along a ray path near vertical incident on the ground. Assuming that the media is isotropic, when SKS wave penetrates the core-mantle boundary, it is radially polarized, with radial component (SV wave), and without trans- 
verse component ( $\mathrm{SH}$ wave). When there are with each other, and then the particle motion changes from the originally linear polarization to elliptic polarization. The parameter pair $(\varphi, \delta t)$ is generally used to describe seismic anisotropy, where $\varphi$ denotes the fast-wave polarization direction, and $\delta t$ is the delay time between fast and slow waves. We can describe $\mathrm{S}$ wave splitting using the parameters of $(\varphi, \delta t)$. Theoretically, the transverse component is zero before the SKS wave propagates through anisotropic layer. If we can find the pair $(\varphi, \delta t)$ which corresponds with the minimum horizontal transverse component, the anisotropy parameters of station are the pair $(\varphi$, $\delta t$ ). The method of SC is a method of measuring the anisotropic parameters $(\varphi, \delta t)$ beneath seismic stations based on the theory of the minimum transverse energy, the errors of the pair $(\varphi, \delta t)$ were determined by $F$-test, where $95 \%$ confidence was used to the error estimation. Figure 2 shows the sample of SKS splitting analysis for Fiji earthquake (2004-11-23, 21h04min with $\left.M_{\mathrm{W}} 5.9\right)$ at station JNX. In Figure 2a, the distinct transverse component denotes the SKS-wave splitting when it propagates through an anisotropic medium, and the particle motion is elliptical (Figure 2c). Contour plot (Figure 2i) of transverse energy on the corrected SKS transverse component computed through the entire range $(\varphi, \delta t)$. From Figure 2i, we can find the minimum (denoted by star), the corresponding $(\varphi, \delta t)$ is the anisotropic result of the station. The transverse component of corrected SKS phase (Figure 2e) is not distinct, the particle motion (Figure $2 \mathrm{~g}$ ) of the corrected SKS phase
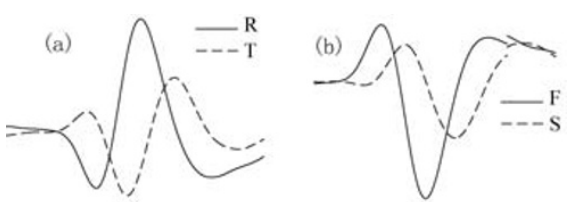

(c)

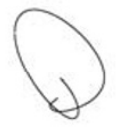

(d)
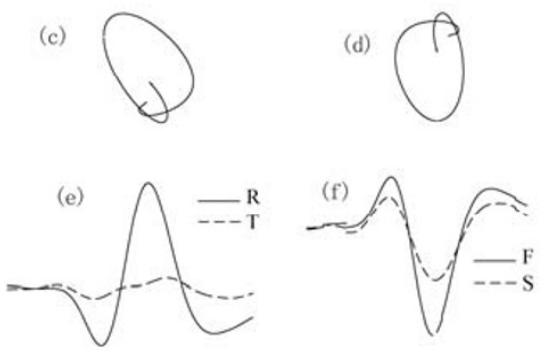

(g)
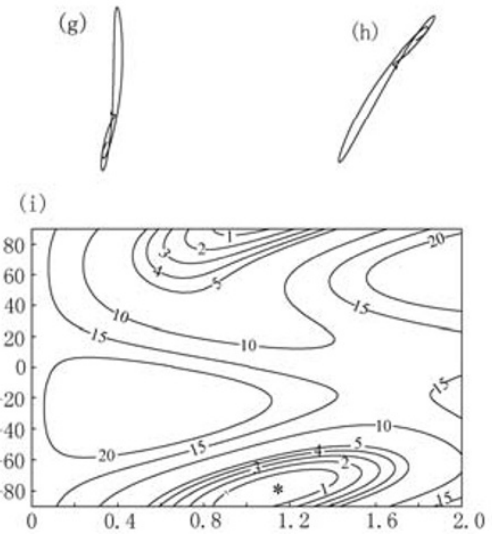

Figure 2 An example of SKS splitting analysis (a) Original SKS phase and (c) particle motion of the original SKS phase in the radial-transverse coordinate system; (e) Corrected SKS phase and (g) particle motion of the corrected SKS phase in the radial-transverse coordinate system; (b) Original SKS phase and (d) particle motion of the original SKS phase in the fast-slow coordinate system; (f) Corrected SKS phase and (h) particle motion of the corrected SKS phase in the fast-slow coordinate system; (i) Contour plot of energy on the transverse component

become linear, and the primary times (Figure $2 \mathrm{f}$ ) of the corrected fast and slow waves become same. Hence, the $\mathrm{S}$ wave splitting parameters are credible.

Firstly, we used the method of Silver and Chan (1991) to make measurement of the anisotropic parameters and their errors determined by individual event with different azimuth. Then, a group of anisotropic parameters from individual teleseismic event at the station are stacked. Suppose that there are $N$ events with different back-azimuths at a station. For $i$ th event $(i=1,2, \cdots, N)$, parameter pair $(\varphi, \delta t)$ corresponds to its transverse energy $E_{t}(\varphi, \delta t)_{i}$. Each transverse energy $E_{t}(\varphi, \delta$ $t)_{i}$ is normalized with the minimum transverse energy, and then we sum $E_{t}(\varphi, \delta t)_{i}$ by $E_{t}(\varphi, \delta t)=\sum$ $E_{t}(\varphi, \delta t)_{i}$. The minimum transverse energy of $E_{t}(\varphi, \delta t)$ is obtained by using the grid searching, and the corresponding parameter pair is the optimal anisotropic parameter pair beneath the station. The 


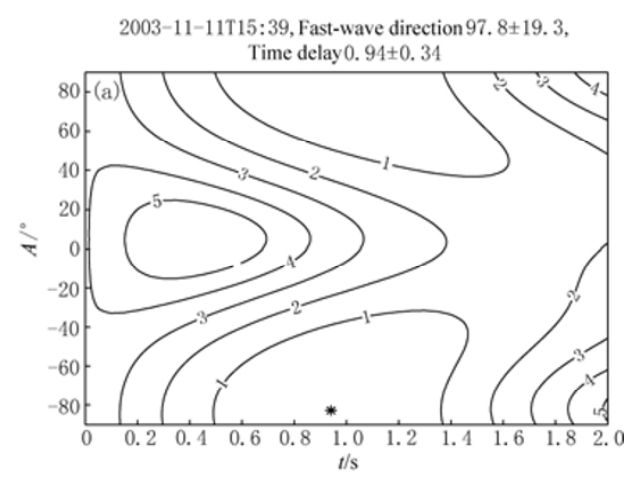

2003-12-16T20:08, Fast-wave direction 108. 6ะ14. 7 ,

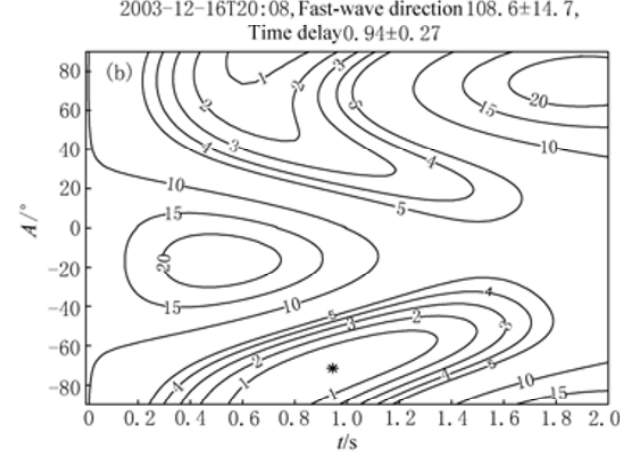

Fast-wave direction $103.3 \pm 6.4$, Time delay $0.87 \pm 0$. 11

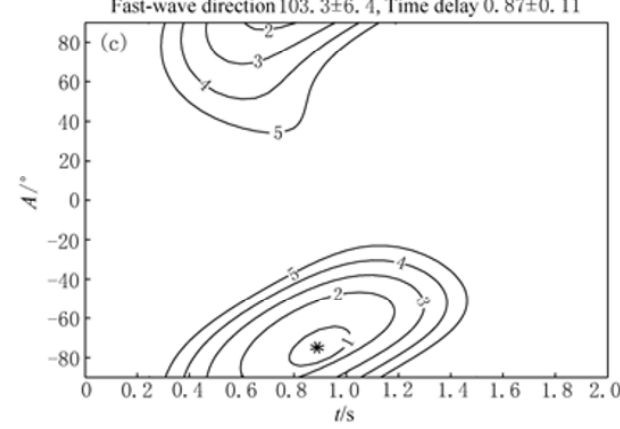

Figure 3 Transverse energy contour of SKS splitting analysis at station JNX in Capital area from two teleseismic events (a) and (b), and the transverse energy contour of the result after stacking (c), where the asterisk denotes the position of optimal parameter pair error estimation is obtained in the similar way. Figure 3 shows that the individual SKS splitting result of 2 teleseismic events (2003-11-11, $15 \mathrm{~h} 39 \mathrm{~min}$ with $m_{\mathrm{b}} 6.1 ; 2003-12-16,20 \mathrm{~h} 08 \mathrm{~min}$ with $\left.m_{\mathrm{b}} 5.7\right)$, which were recorded by JNX station, are compared to the result by using the stacking analysis. It is obvious that the error of the stacked result decreases significantly, comparing with the errors of the individual event.

\section{Results and analysis}

We use the technique of stacking analysis to determine anisotropic parameters at 49 stations in Capital area and the results for each station are listed in Table 1. Figure 4 shows the scattering of shear-wave splitting parameters by stations. In general, the permanent stations have been kept in operation for longer time under the good observational environment with low background noise, hence lots of available teleseismic events were obtained, and thus SKS splitting results have high quality. In Table 1 , the results at most stations are good, in which the errors of fast-wave directions are less than $10^{\circ}$, and the errors of delay times is less than $0.2 \mathrm{~s}$. However, we do not gain any reliable splitting parameters at 3 stations (CHD, QIX and YAY) because the azimuths of events possibly parallel or perpendicular to the fast-wave directions. We do not gain the stacking results at 2 stations (LIQ and NKY) due to a big scatter for the fast-wave directions, which may be related to complex tectonic setting (e.g., multilayer anisotropy and titled fault) and data recorded.

Based on the polarization analysis from teleseismic SKS data recorded at the 49 stations in Capital area, we plot an anisotropic image of the upper mantle shown in Figure 5. The fast-wave polarization directions are mostly WNW-ESE, which show good consistency. The delay time between fast and slow waves falls into the interval $[0.56 \mathrm{~s}, 1.56 \mathrm{~s}]$, and the delay time at most stations is about $1 \mathrm{~s}$.

The BJT result in this study is consistent with the result obsvered by ZHENG and GAO (1994). The BJT and HNS restuls are consistent with the results obsevered by LUO et al (2004) and Liu et al (2008). However, our results at most stations are not consistent with the results 
obsvered by Zhao and Zheng (2005), the inconsistency is possibly due to different SKS splitting measurement techniques and different data processing and selection criteria used by the studies.

\section{Discussion and conclusions}

\subsection{Localization and thickness of anisotropic layer}

The delay time of SKS splitting is a consequence of strain-induced lattice preferred orienta Table 1 Splitting parameters for SKS phase in Capital area

\begin{tabular}{|c|c|c|c|c|c|c|c|}
\hline No. & Code & Station & $\varphi /^{\circ}$ & $\Delta \varphi /^{\circ}$ & $\delta t / \mathrm{s}$ & $\Delta \delta t / \mathrm{s}$ & Number \\
\hline 1 & BBS & Babaoshan & 102.0 & 7.5 & 0.87 & 0.05 & 20 \\
\hline 2 & $\mathrm{BDH}$ & Beidaihe & 138.2 & 5.7 & 0.90 & 0.23 & 6 \\
\hline 3 & BJT & Beijing & 111.7 & 1.9 & 0.89 & 0.08 & 25 \\
\hline 4 & $\mathrm{CHC}$ & Chicheng & 111.8 & 3.4 & 0.94 & 0.07 & 33 \\
\hline 5 & $\mathrm{CHD}$ & Chengde & & & & & 0 \\
\hline 6 & $\mathrm{CHL}$ & Changli & 134.8 & 5.5 & 0.75 & 0.26 & 6 \\
\hline 7 & DAS & Dashan & 107.4 & 11.2 & 1.56 & 0.17 & 8 \\
\hline 8 & $\mathrm{DHC}$ & Dahuichang & 104.7 & 7.9 & 0.74 & 0.07 & 27 \\
\hline 9 & $\mathrm{DOH}$ & Douhe & 105.7 & 10.3 & 0.86 & 0.23 & 6 \\
\hline 10 & FEN & Fengning & 108.5 & 2.4 & 1.15 & 0.08 & 20 \\
\hline 11 & GAN & Gangnan & 106.6 & 6.3 & 1.11 & 0.21 & 18 \\
\hline 12 & HBZ & Huangbizhuang & 113.4 & 3.8 & 1.29 & 0.18 & 14 \\
\hline 13 & HNS & Hongshan & 104.2 & 1.8 & 1.16 & 0.07 & 29 \\
\hline 14 & HUA & Huaian & 131.5 & 4.1 & 0.78 & 0.11 & 14 \\
\hline 15 & JIX & Jixian & 97.6 & 8.9 & 0.68 & 0.10 & 12 \\
\hline 16 & $\mathrm{JNX}$ & Jingxing & 100.1 & 3.6 & 0.90 & 0.07 & 19 \\
\hline 17 & KUC & Kuancheng & 101.8 & 4.1 & 1.19 & 0.07 & 16 \\
\hline 18 & LAY & Laiyuan & 119.8 & 6.0 & 0.75 & 0.26 & 5 \\
\hline 19 & LBG & Lamagoumen & 110.3 & 9.7 & 1.30 & 0.27 & 2 \\
\hline 20 & LBP & Liubinpu & 106.1 & 5.9 & 0.80 & 0.08 & 14 \\
\hline 21 & LIQ & Lingqiu & & & & & 13 \\
\hline 22 & LLM & Liulimiao & 78.0 & 5.0 & 0.81 & 0.10 & 14 \\
\hline 23 & LQS & Longquansi & 114. 9 & 3.3 & 0.84 & 0.13 & 12 \\
\hline 24 & LUQ & Luquan & 103.9 & 3.0 & 1.00 & 0.08 & 11 \\
\hline 25 & MDY & Madaoyu & 100.7 & 4.0 & 0.90 & 0.08 & 16 \\
\hline 26 & MIY & Miyun & 102.5 & 9.4 & 0.74 & 0.07 & 19 \\
\hline 27 & NKY & Niukouyu & & & & & 18 \\
\hline 28 & QIL & Qinglong & 106.3 & 11.4 & 0.89 & 0.18 & 4 \\
\hline 29 & QIX & Qianxi & & & & & 0 \\
\hline 30 & SFS & Shangfangshan & 114.3 & 7.3 & 0.70 & 0.29 & 5 \\
\hline 31 & SSL & Shisanling & 95.2 & 8.3 & 0.65 & 0.08 & 14 \\
\hline 32 & SUZ & Suizhong & 112.5 & 9.5 & 0.65 & 0.08 & 12 \\
\hline 33 & SZL & Sizuolou & 112.1 & 11.6 & 0.56 & 0.34 & 12 \\
\hline 34 & TLK & Taolinkou & 111.7 & 6.9 & 0.88 & 0.26 & 5 \\
\hline 35 & TST & Taishitun & 104.0 & 6.0 & 0.68 & 0.05 & 18 \\
\hline 36 & WAX & Wanxian & 117.7 & 2.2 & 1.16 & 0.17 & 4 \\
\hline 37 & XBZ & Xibazi & 114.8 & 4.9 & 0.7 & 0.08 & 24 \\
\hline 38 & XIL & Xinglong & 105.0 & 11.1 & 0.82 & 0.21 & 5 \\
\hline 39 & XIT & Xingtang & 107.9 & 6.0 & 0.80 & 0.19 & 10 \\
\hline 40 & XLD & Xinglongdong & 111.0 & 11.6 & 0.73 & 0.23 & 4 \\
\hline 41 & YAY & Yangyuan & & & & & 0 \\
\hline 42 & YIX & Yixian & 137.8 & 3.0 & 1.31 & 0.19 & 6 \\
\hline 43 & YUS & Yuanshi & 101.1 & 4.1 & 1.12 & 0.07 & 25 \\
\hline 44 & $\mathrm{ZAH}$ & Zanhuang & 103.9 & 2.6 & 1.12 & 0.05 & 32 \\
\hline 45 & ZJK & Zhangjiakou & 94.7 & 5.3 & 0.65 & 0.04 & 26 \\
\hline 46 & ZHB & Zhangbei & 111.9 & 3.4 & 0.84 & 0.13 & 10 \\
\hline 47 & ZHL & Zuolu & 104.0 & 10.4 & 0.68 & 0.24 & 3 \\
\hline 48 & ZHT & Zhaitang & 106.9 & 3.9 & 0.77 & 0.11 & 12 \\
\hline 49 & ZUH & Zunhua & 121.9 & 5.5 & 0.79 & 0.15 & 5 \\
\hline
\end{tabular}

Note: $\varphi$ and $\Delta \varphi$ is the fast-wave direction and its error, $\delta t$ and $\Delta \delta t$ is the delay time and its error. 

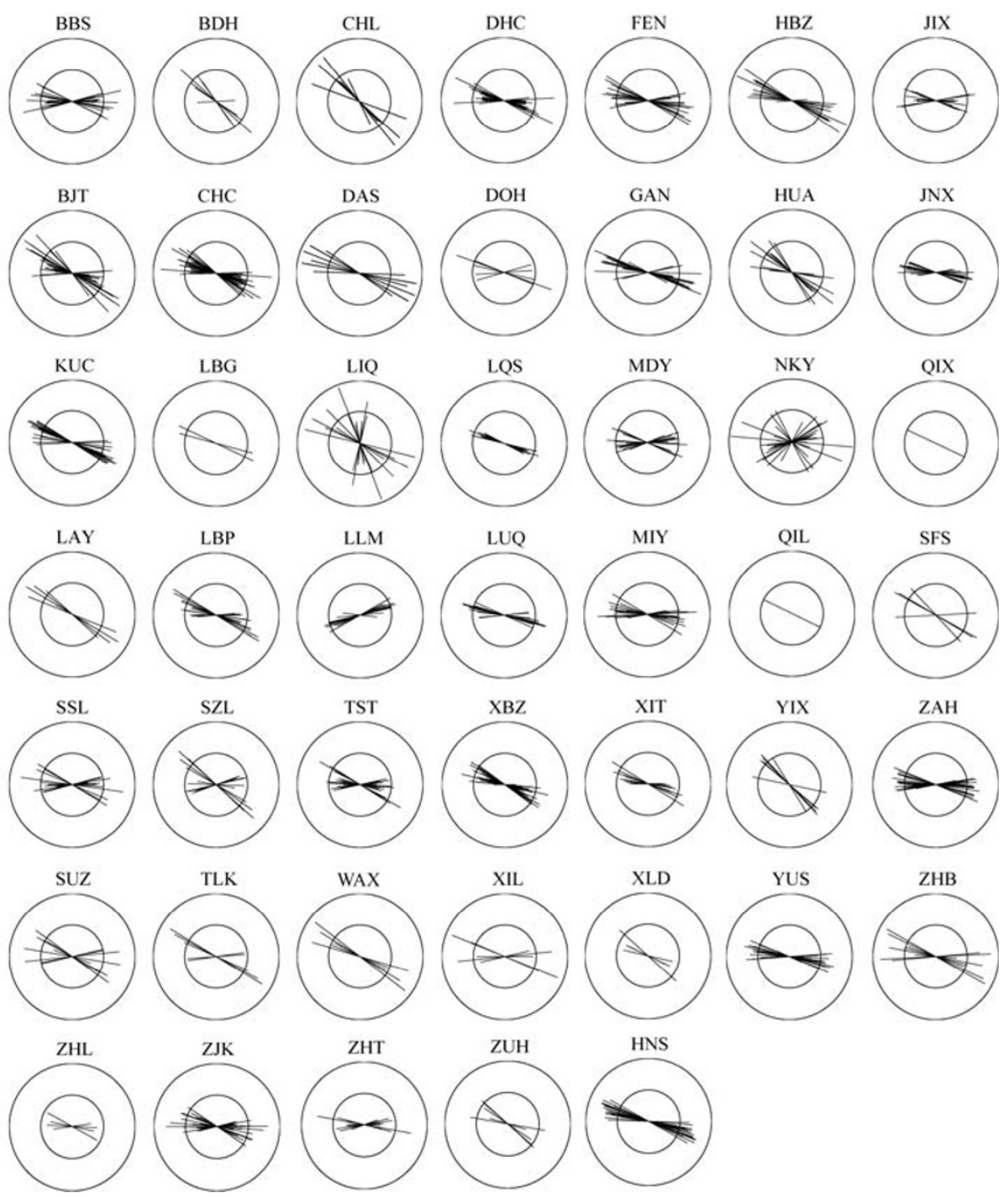

Figure 4 Results of anisotropy measurements of SKS splitting by stations Radius of concentric circle denotes the delay time between fast and slow waves. Radius of the inner circle is $1 \mathrm{~s}$, outward circle is $2 \mathrm{~s}$. The line direction denotes the fast-wave direction, the line length denotes the delay time

tion of olivine crystals. The analysis of the contents of olivine and other mineral in upper mantle and laboratory measurement of olivine lattice inferred anisotropy degree of 0.04 , in this case, $1 \mathrm{~s}$ of delay time corresponds to $115 \mathrm{~km}$ (McNamara et al, 1994). Thus we deduce the anisotropic thickness of upper mantle in Capital area is about $64 \sim 179 \mathrm{~km}$ based on the delay time of $0.56 \sim 1.56 \mathrm{~s}$, the average thickness is about $120 \mathrm{~km}$. There exists a large variation of the thickness of anisotropic layer, which implies that the inside lithospheric deformation is asymmetrical beneath the study area. Other geophysical results show that the structure of the crust and upper mantle exist obviously laterally inhomogeneities (Huang and Zhao, 2004; QI et al, 2006). According to the surface wave anisotropy beneath Chinese mainland, there exists strong anisotropy in depth of 70 150 km (PENG et al, 2007). The east part of North China Craton has experienced large-scale 


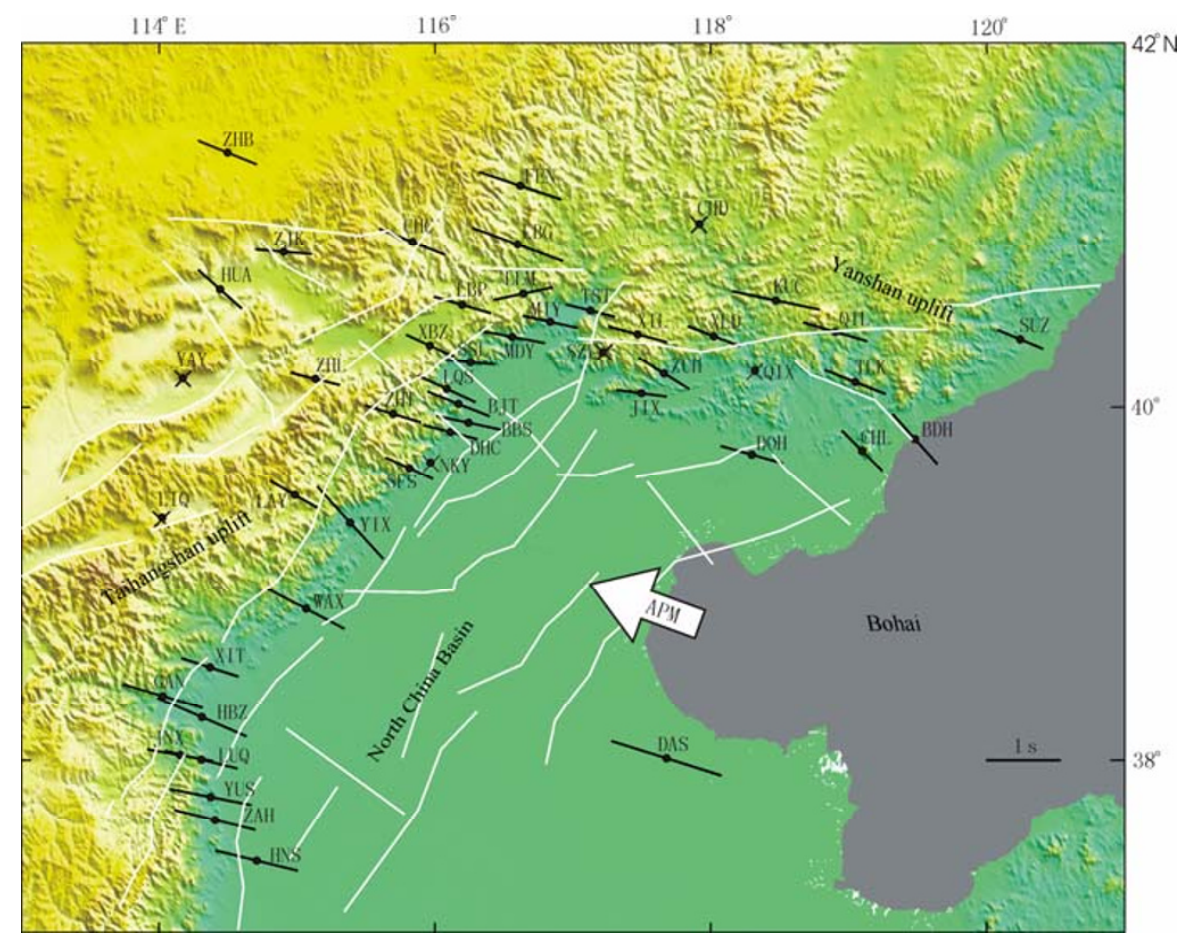

Figure 5 Anisotropic image of upper mantle and regional geologic setting in Capital area The orientations and length of each black line indicate the fast-wave polarization direction and the delay time, respectively; Black forks denote null results; White arrowhead represents the direction of absolute plate motion; White curved lines show major faults

lithospheric activation process in the Cenozoic-Mesozoic, which caused the thinning of lithosphere $(>100 \mathrm{~km})(\mathrm{ZHU}, 2007)$. The lithosphere thickness of Capital area is about $80 \mathrm{~km}$ (An and Shi, 2006), and the anisotropic thickness of the study is about $120 \mathrm{~km}$. Hence, we think that the anisotropy in Capital area not only come from the upper mantle lithosphere, but also from the asthenosphere.

\subsection{Cause of anisotropy}

The upper mantle anisotropy is a consequence of strain-induced lattice preferred orientation of olivine crystals, it reflects the past and present internal deformation of the subcontinental upper mantle by tectonic episodes. Hence, the kinematic models of the Earth's interior can be inferred (Silver and Chan, 1991). There are various causes resulting in the mantle deformation. Among them, the plate motion is the most direct cause. To a great extent, the plate motion determines the degree of the mantle anisotropy. Generally, the direction of absolute plate motion (APM) is consistent with the fast-wave polarization direction, which implies that mantle flow play significant role in upper mantle anisotropy (Vinnik et al, 1992). In Capital area, the WNW APM direction using HS3-NUVEL1a model (Gripp and Gordon, 2002) is consistent with the fast-wave direction, which images the upper mantle anisotropy is mainly caused by the mantle flow of the subduction of the Pacific plate to Eurasian plate (Figure 5). The subduction of the Pacific plate has resulted in the asthenospheric deformation beneath Capital area, and made the alignment of upper mantle peridotite lattice parallel to the deformation direction.

North China has undergone rifting and widespread extension during Late Mesozoic to Ceno- 
zoic. The upper crustal tectonic extensional direction is WNW-ESE in Capital area (WANG et al, 2007b). The WNW-ESE trending extensional direction is consistent with the fast-wave direction, which implies the extension make the direction of lithosphere deformation parallel to the fast-wave direction, and the shallow material extensional deformation and the deep material deformation model are consistent. Due to the northward compression of India plate on the southwest of China, the northward and westward subduction of Pacific plate and Philippine Sea Plate on the east, and the obstruction of Siberian platform on the north, China continent shows the characteristics of compression in the west and extension in the east, and the continental material is eastward and southward extruded (DENG et al, 1996; QIU et al, 2004). The GPS measurements (MA et al, 2001; NIU et al, 2005) show the eastward and southward trending velocity directions, which are consistent with the fast-wave direction. The consistency implies that the crustal deformation and the upper mantle deformation are consistent. Hence, the deformation model of the crust and upper mantle is possibly vertically coherent deformation.

\subsection{Conclusions}

In summary, the fast-wave polarization direction is basically WNW-ESE direction, and the delay time falls into the interval from $0.56 \mathrm{~s}$ to $1.56 \mathrm{~s}$. We deduce the anisotropic thickness of upper mantle in Capital area is about $64 \sim 179 \mathrm{~km}$ based on the delay time. The research results imply that the upper mantle anisotropy is mainly caused by the subduction of the Pacific plate to Eurasian plate. The subduction of the Pacific plate has resulted in the asthenospheric deformation beneath Capital area, and made the alignment of upper mantle peridotite lattice parallel to the deformation direction. The collision between the plates made the crust of western China thickening and uplifting and material eastwards extruding, and then caused the upper mantle flow eastwards, and made the direction of upper mantle material deformation parallel to the fast-wave direction. The deformation of the crust and upper mantle is possibly vertically coherent deformation by comparing the fast-wave polarization direction with the direction of lithospheric extension and the GPS velocity direction.

\section{References}

An M and Shi Y. 2006. Lithospheric thickness of the Chinese continent [J]. Phys Earth Planet Ints, 159: 257-266.

CHANG Li-jun, WANG Chun-yong, DING Zhi-feng. 2006. A study on SKS splitting beneath the Yunnan region [J]. Chinese J Geophys, 49: 197-204 (in Chinese).

CHANG Li-jun, WANG Chun-yong, DING Zhi-feng, et al. 2008. Seismic anisotropy of upper mantle in the northeastern margin of the Tibetan Plateau [J]. Chinese J Geophys, 51(2): 431-438 (in Chinese).

DENG Jin-fu, ZHAO Hai-ling, MO Xuan-xue, et al. 1996. Continental Roots-plume Tectonics of China: Key to the Continental Dynamics [M]. Beijing: Geological Publishing House: 59-82 (in Chinese).

DING Zhi-fneg and ZENG Rong-sheng. 1996. Observation and study of shear wave anisotropy in Tibetan Plateau [J]. Chinese J Geophys (Acta Geophysica Sinica), 39(2): 211-219 (in Chinese).

GAO Yuan, ZHENG Si-hua, ZHOU Hui-lan. 1999. Polarization patterns of fast shear wave in Tangshan region and their variations [J]. Chinese J Geophys, 42(2): 228-232 (in Chinese).

Gripp A E and Gordon R G. 2002. Young tracks of hotspots and current plate velocities [J]. Geophys J Int, 150: $321-361$.

Huang J and Zhao D. 2004. Crustal heterogeneity and seismotectonics of the region around Beijing [J]. Tectonophysics, 385: 159-180.

JIANG Mei, XU Zhi-qi, Hirn A, et al. 2001. Teleseismic anisotropy and corresponding features of upper mantle in Tibetan Plateau and its neighboring areas [J]. Acta Geoscientia Sinica, 22(2): 111-116 (in Chinese).

LAI Yuan-gen, LIU Qi-yuan, CHEN Jiu-hui, et al. 2006. Shear wave splitting and the features of the crustal stress field in the Capital Circle [J]. Chinese J Geophys, 49(1): 189-196 (in Chinese).

Liu K H, Gao S S, Gao Y, et al. 2008. Shear wave splitting and mantle flow associated with the deflected Pacific slab beneath northeast Asia [J]. J Geophys Res, 113: B01305, doi: 10.1029/2007JB005178.

LÜ Qing-tian, MA Kai-yi, JIANG Mei. 1996. Seismic anisotropy beneath Southern Tibet [J]. Acta Seismologica Sinica, 9(2): $279-288$.

LUO Yan, HUANG Zhong-xian, PENG Yan Jü, et al. 2004. A study on SKS wave splitting beneath the China mainland and adjacent regions [J]. Chinese J Geophy, 47(5): 812-821 (in Chinese).

MA Zong-jin, CHEN Xin-lian, YE Shu-hua, et al. 2001. Contemporary crustal movement of continental China obtained by global posi- 
tioning system (GPS) measurement [J]. Chinese Science Bulletin, 46(13): 1 118-1 120 (in Chinese).

McNamara D, Owens T, Silver P G, et al. 1994. Shear-wave anisotropy beneath the Tibetan Plateau [J]. J Geophys Res, 99: 13 65513665.

NIU Zhi-jun, WANG Ming, SUN Han-rong, et al. 2005. Contemporary velocity field of crustal movement of Chinese mainland from Globle Positioning System measurements [J]. Chinese Science Bulletin, 50(8): 839-848 (in Chinese).

PENG Yan-jü, HUANG Zhong-xian, SU Wei, et al. 2007. Anisotropy in crust and upper mantle beneath China continent and its adjacent seas [J]. Chinese J Geophys, 50(3): $752-759$ (in Chinese).

QI Cheng, ZHAO Da-peng, CHEN Yi, et al. 2006. 3-D P and S wave velocity structures and their relationship to strong earthquakes in the Chinese capital region [J]. Chinese J Geophys, 49(3): 805-815 (in Chinese).

QIU Rui-zhao, DENG Jin-fu, ZHOU Su, et al. 2004. The types of lithosphere in North China: The proof from geology and geophysics [J]. Science in China (Series D), 34(8): 689-711 (in Chinese).

Silver P G and Chan W W. 1991. Shear-wave splitting and subcontinental mantle deformation [J]. J Geophys Res, 96: 16 429-16454.

Vinnik L P, Farra V, Romanowicz B. 1989. Azimuthal anisotropy in the Earth from observations of SKS at Geoscope and NARS broadband stations [J]. Bull Sesim Soc Amer, 79: 1542-1 558.

Vinnik L P, Makeyeva L I, Milev A, et al. 1992. Global patterns of azimuthal anisotropy and deformations in the continental mantle [J]. Geophys J Int, 111: 433-447.

WANG Chun-yong, CHANG Li-jun, LÜ Zhi-yong, et al. 2007a. Seismic anisotropy of upper mantle in eastern Tibetan Plateau and related crust-mantle coupling pattern [J]. Science in China (Series D), 37(4): 495-503 (in Chinese).

WANG Tao, ZHENG Ya-dong, ZHANG Jin-jiang, et al. 2007b. Some problems in the study of Mesozoic extensional structure in the North China craton and its significance for the study of lithospheric thinning [J]. Geolog Bull China, 26(9): $1154-1166$ (in Chinese).

Wolfe C J and Silver P G. 1998. Seismic anisotropy of oceanic upper mantle: Shear wave splitting methodologies and observations [J]. J Geophys Res, 103(B1): 749-771.

WU Jing, GAO Yuan, CHEN Yun-tai, et al. 2007. Seismic anisotropy in crust in Northwest Beijing area [J]. Chinese J Geophys, 50(1): 210-221 (in Chinese).

Zhao L and Zheng T Y. 2005. Using shear wave splitting measurements to investigate the upper mantle anisotropy beneath the North China Craton: Distinct variation from east to west [J]. Geophys Res Lett, 32: L10309, doi:10.1029/2005GL022585.

ZHENG Si-hua and GAO Yuan. 1994. Azimuth anisotropy of lithosphere of continental China [J]. Acta Seismologica Sinica, 16(2):131-140 (in Chinese).

ZHU Ri-xiang. 2007. Deep earth exploration: A case study from the North China Craton [J]. Progress in Geophys, 22(4): $1090-1100$ (in Chinese). 